
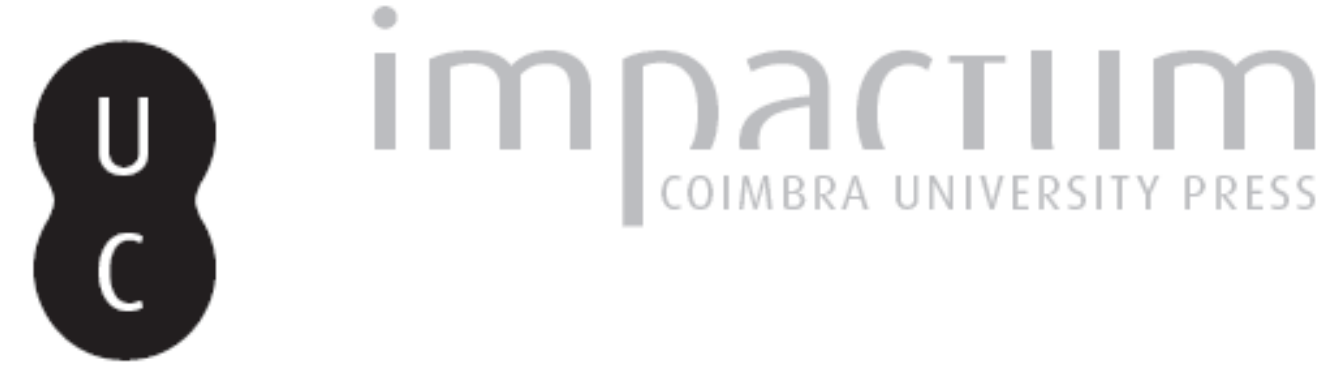

\title{
[Recensão a] Vicente Ramón Palerm \& Jorge Bergua Cavero, Plutarco. Obras morales y de costumbres. Tomo IX
}

\author{
Autor(es): $\quad$ Vicente Sánchez, Ana \\ Publicado por: International Plutarch Society \\ URL \\ persistente: \\ URI:http://hdl.handle.net/10316.2/37613 \\ DOI: \\ DOI:http://dx.doi.org/10.14195/0258-655X_3_9
}

Accessed : $\quad$ 26-Apr-2023 14:21:49

A navegação consulta e descarregamento dos títulos inseridos nas Bibliotecas Digitais UC Digitalis, UC Pombalina e UC Impactum, pressupõem a aceitação plena e sem reservas dos Termos e Condições de Uso destas Bibliotecas Digitais, disponíveis em https://digitalis.uc.pt/pt-pt/termos.

Conforme exposto nos referidos Termos e Condições de Uso, o descarregamento de títulos de acesso restrito requer uma licença válida de autorização devendo o utilizador aceder ao(s) documento(s) a partir de um endereço de IP da instituição detentora da supramencionada licença.

Ao utilizador é apenas permitido o descarregamento para uso pessoal, pelo que o emprego do(s) título(s) descarregado(s) para outro fim, designadamente comercial, carece de autorização do respetivo autor ou editor da obra.

Na medida em que todas as obras da UC Digitalis se encontram protegidas pelo Código do Direito de Autor e Direitos Conexos e demais legislação aplicável, toda a cópia, parcial ou total, deste documento, nos casos em que é legalmente admitida, deverá conter ou fazer-se acompanhar por este aviso.

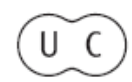




\section{PLOUTARCHOS, n.s.}

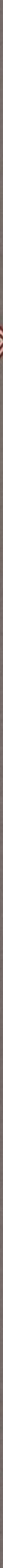

UNIVERSITY OF MÁLAGA (SPAIN)

UtAH STATE UNIVERSity, LOGAN, UTAH (U.S.A.) 
niens et sur une réécriture plus décisive en core de l'histoire grecque. L'hypothèse de C. Bearzot rappelée par $\mathrm{R}$ Sánchez, selon laquelle la Grèce de Pausanias serait la Grè ce de l'Amphictionie pose la question d'un livre thessalien, car l'Amphictionie pyléodelphique ne saurait se concevoir sans une présence thessalienne.

Les deux ouvrages font également le point sur les transformations de l'institution à l'époque impériale, transformations qui semblent dater de la fin du règne d'Auguste ou de celui de Tibère, à l'exception de la création sous Hadrien de la charge vraisem blablement viagère d'helladarque des Amphictions. Outre la disparition de la dis tinction entre hiéromnémon et pylagore par une confusion des fonctions assumées par la même personne qualifiée simplement d'amphiction, les innovations concernent donc l'apparition de nouvelles charges, celle d'agonothète des Pythia chargé de la présiden ce du concours, celle d'épimélète du conseil amphictionique aux larges attributions es sentiellement administratives et financières dans les deux domaines principaux d'inter vention de l'Amphictionie, la gestion de la fortune du dieu' et l'organisation des Pythia. Ces deux tâches sont assumées la durée d'une pythiade, mais l'agonothésie peut être revêtue plus d'une fois, à la différence de la charge d'épimélète. La documentation laisse supposer que tous les membres de l'Amphictionie n'étaient pas également qualifiés pour fournir des agonothètes et des épimélètes et qu'il y ait eu en ce domaine des chan gements sous les Flaviens et sous Hadrien qui sont vraisemblablement liés aux réfor mes de 67 et de 125 . On devine que le rôle de Domitien a dû être plus important que le laisse supposer une tradition littéraire plus respectueuse de la damnatio memoriae du dernier des Flaviens que les autorités en charge du sanctuaire qui ont laissé visibles la dédicace des travaux effectués au temple en 84 (R. FLACELIÈRE, $F D$ III 4, 120) et la correspondance relative aux Pythia de 90 (H. POMTOW, $S^{3} G^{3}$ 821B-E) et certains ont voulu voir cet empereur dans le $\kappa \alpha \theta \eta \gamma \beta$ óv $\alpha$ évoqué à la fin du De Pythiae oraculis.

Le lecteur ne peut que souscrire à ce qu'écrit R Sánchez (p. 463) sur la façon dont les auteurs tardifs ont exagéré l'importance politique et judiciaire de l'Amphictionie par patriotisme et idéalisme : « leurs descrip tions ne correspondent à aucune réalité, mais elles reflètent leurs conceptions de ce qu'au rait dû être (souligné par l'auteur) la Grèce classique : fédérée, réglant ses différends par l'arbitrage, plutôt que par la guerre, et unie contre l'envahisseur, qu'il soit perse, macé donien, gaulois, ou même romain ». Cette conclusion qui est celle des auteurs de ces deux monographies sonne comme une invi tation pour tous les commentateurs de textes à garder une prudence lucide et à ne pas se livrer à des épanchements lyriques sur l'Amphictionie pyléo-delphique.

Anne Jac que min

Université Marc Bloch - Strasbourg jacquemi@umb.u-strasbg.fr

Vicente Ramón Palerm \& Jorge Bergua Cavero, Plutarco. Obras morales y de costumbres. Tomo IX. Introducción, traducción y notas de -, Madrid, Gredos, 2002, 411 pp. ISBN 84-249-2322-7.

Este volumen reúne diversos tratados de Moralia; algunos muy conocidos, como Sobre la malevolencia de Heródoto, pero

La thèse de D. Rousset, Le territoire de Delphes et la terre d'Apollon, Bibliothèque des Écoles françaises d'Athènes et de Rome, fascicule 310, École française d'Athènes, 2002, fait le point sur le devenir de la terre sacrée durant l'époque impériale. 
otros lo son menos, debido a su complejidad temática, a su brevedad, a su peculiar forma retòrica o a su difícil clasificación. Ambos traductores dan cuenta del género al que pueden adscribirse las composiciones, de su estructura y desarrollo, de la impronta de la retórica, de la finalidad última del autor y del significado de estas orbitales; destacan, ade más, su importancia y valor dentro de la obra plutarquea y también el uso de la tradición en cada tema, así como su ubicación en el ámbito literario griego; acompañan la labor de traducción con el empleo de una rica bibliografía que puede suponer un útil ins trumento para el lector; y complementan esta edición con un exhaustivo índice de nombres propios sito en las páginas finales del volumen (pp. 399-409).

Las traducciones son un claro exponente del propósito de esta colección de textos clá sicos, pues su carácter divulgativo pero a la vez rigurosamente científico da como resul tado una lectura amena e instructiva. Si bien algunos de los textos que integran este volu men pueden parecer insignificantes debido a su extensión y poca trascendencia tradicio nalmente, son una muestra valiosa de la completa formación y del pensamiento de nuestro polígrafo en una época en la que la retórica llegaba a todos los campos de la lite ratura y los fenómenos naturales eran una cuestión de interés general.

Tanto el Profesor Ramón como el Profe sor Bergua son profundos conocedores de la obra y el pensamiento de Plutarco debido a sus investigaciones que han sido continua das desde la elaboración de sus respectivas tesis doctorales sobre el Bios plutarqueo y sobre la tradición de Plutarco en España.

Jorge Bergua Cavero ha realizado la tra ducción, introducción y notas de los tratados Sobre la inteligencia de los animales y Los animales son racionales o Grilo. El primero de ellos (pp. 253-335) es un diálogo que expone la difícil cuestión de la inteligencia animal y plantea argumentos a favor bien de los animales terrestres, bien de los acuáticos, terminando la obra Plutarco sin decantarse por uno u otro grupo, ya que, al parecer, su objetivo principal era refutar a los estoicos que defendían la irracionalidad de los ani males. El traductor refiere el contexto y los antecedentes a partir de los que pudo des arrollarse este tratado en cuestión, haciendo una comparación con la posterior evolución que este tema ha recibido, y asimismo nos proporciona la pervivencia que esta obrita de Plutarco ha tenido. Las referencias biblio gráficas sobre este tratado se complementan con trabajos relacionados con su temática, que, además, serán útiles para la otra traduc ción que J. Bergua presenta en este volumen.

La introducción de Los animales son racionales (pp. 337-368) nos ofrece un breve esbozo de la historia de este opúsculo, de cro nología incierta y autoría discutida, aunque para J. Bergua la adscripción a Plutarco es segura. Acaba de forma abrupta, por lo que la mayor parte de la crítica piensa que es una composición inacabada. Junto al comentario de la estructura, nos indica el traductor los paralelismos con otras partes de la obra plu tarquea y las conexiones con diferentes corrientes filosóficas, puesto que la finalidad, además de la crítica de los vicios humanos, consiste en un ataque a las ideas estoicas sobre los animales. El tratado, que comienza como un diálogo ameno y divertido entre Ulises y Circe primero, Ulises y Grilo después, consis te en su mayor parte en un discurso retórico pomposo, en el que el cerdo Grilo, portavoz de los hombres convertidos en bestias por Circe, declara las bondades y ventajas de la vida ani mal. La obra parece interrumpirse en medio de la discusión sobre la conciencia de dios que pueden poseer los animales.

El texto que J. Bergua sigue para ambos tratados es el de C. Hubert (revisado por $\mathrm{H}$. Drexler) de la editorial Teubner (Leipzig, 1959), aunque ha manejado el de W. C. 
Hembold de la Loeb (Londres-Cambridge, Mass., 1957) y, para Grilo, también el de G. Indelli (del Corpus Plutarchi Moralium, Nápoles, 1995). La traducción consigue una lectura sencilla, ágil y amena, y está dotada, además, de unas notas que contextualizan constantemente al lector, proporcionan las referencias a las citas que Plutarco utiliza y dan cuenta de los juegos de palabras e ironí as presentes en el original griego.

Sobre la malevolencia de Heródoto (pp. 778) es la primera de las composiciones que V. Ramón Palerm presenta en este volumen. En ella Plutarco refiere las características de un escritor malevolente, para después demostrar mediante ejemplos que Heródoto posee tales cualidades. La introducción facilita un claro esquema de la estructura y evidencia la finali dad última de la obrita: para nuestro traductor, que recoge las principales tendencias críticas, la intención polémica y retórica predomina sobre cualquier otra, siendo además un ejem plo acabado de las muchas ejercitaciones retó ricas que componen los Moralia, y en este caso concretamente nos hallamos ante una epídeixis retórica. A esta presentación añade la mención y juicio de los manuscritos existentes; se sirve de la edición de L. Pearson en la editorial Loeb (Londres-Cambridge, Mass., 1970 [=1965]), aunque en señaladas ocasiones desestima sus propuestas y se decanta por lecturas de los códices o de otros editores. Encontramos una traducción rigurosa y muy cuidada, provista de unas minuciosas notas que ayudan al lector a identificar los personajes, situaciones y citas que aparecen, además de trabajar con una bibliografía muy completa.

En segundo lugar aparecen en este volu men las Cuestiones sobre la Naturaleza (pp. 79-117). Son para V. Ramón, de acuerdo con F. H. Sandbach, una colección de notas com puestas bajo la influencia de la escuela aris totélica, aunque han recibido diversas inter pretaciones en cuanto a su clasificación genérica. A pesar de que se ha cuestionado su autoría, ciertos rasgos inclinan al traduc tor a afirmar la procedencia plutarquea, al tiempo que nos ofrece una descripción de la obra y menciona sus paralelos en la literatu ra griega. Acompaña a esta versión el uso de una cuidada bibliografía, dados los escasos estudios que existen sobre este opúsculo; las notas nos ofrecen la referencia de las citas que Plutarco utiliza, su presencia en otras partes de su extensa obra y nos explican la traslación de ciertos términos que adquieren un sentido téc nico en este tipo de composición. El texto que sigue esta preciosa traducción es el de F. H. Sandbach de la editorial Loeb (LondresCambridge, Mass., 1970 [=1965]), aunque en diversas ocasiones elige V. Ramón la lectura de un códice o de otro editor.

Sobre la cara visible de la luna (pp. 119198) es un diálogo de diatriba en el cual el elemento científico es un factor importante, pero son los ámbitos filosófico y religioso a los que Plutarco confiere mayor valor, aun que evidencia su erudición en ciencias exac tas, geometría, física, matemáticas y astro nomía, como bien señala $\mathrm{V}$. Ramón en su pre facio. Con la descripción del contenido, de sus personajes, de las tres principales partes del diálogo y el análisis de los posibles ante cedentes, nos demuestra el traductor que nos encontramos ante una composición exquisita mente elaborada y más trabada que otras con este mismo carácter científico: una serie de personajes va a ir revelando las doctrinas de las diferentes escuelas sobre la luna para con cluir con el relato de un mito simbólico que desvelará la verdadera importancia de la luna en clave místico-religiosa. La introducción nos ofrece, asimismo, un análisis de los manuscritos conservados, con el problema añadido del delicado estado en que se halla el texto; la edición empleada es la de $\mathrm{H}$. Chemiss de la Loeb (Londres-Cambridge, Mass., 1968 [=1957]) con alguna variante procedente de los códices o de otro editor. La traducción refleja el carácter técnico pero a la vez coloquial que el contenido y la forma del 
texto griego requerían, cuya comprensión viene facilitada por unas jugosas notas, con siguiendo una clara y agradable lectura.

En Sobre el principio del frío (pp. 199234) indaga Plutarco en los elementos que pueden originar el frío, para lo cual nos da cuenta de las principales teorías que corrían por entonces. Nos explica V. Ramón la críti ca a la corriente estoica que postulaba el aire como integrante primero de ese origen; el agua recibe un mejor tratamiento por parte de Plutarco, pero parece ser la tierra el ele mento por el que nuestro autor se decanta. Termina con una advertencia a Favorino, a quien va dirigido el opúsculo, sobre la cau tela con que debe manejar tanto los argu mentos del propio Plutarco como cuales quiera otros, dado que es la postura más pru dente y productiva. En este tratado, nos señala V. Ramón, predomina, sobre la exhi bición retórica, el pensamiento epistemoló gico, de clara influencia platónica. Se atiene a la edición de W. C. Hembold en la Loeb (Londres-Cambridge, Mass., 1968 [=1957]), con alguna variante. La traducción solventa satisfactoriamente los problemas terminoló gicos que el vocabulario técnico utilizado presenta, y consigue, además, en un español fluido y agradable, reproducir el espíritu científico de la obra griega, además de las intenciones artísticas de Plutarco.

La crítica en general, y V. Ramón con ella, reconoce en Sobre si es más útil el agua o el fuego (pp. 235-251 ) un tratado de carácter retórico-epidíctico, en el que los problemas filosó fico-científicos apenas se plantean. Su atribu ción a Plutarco ha sido cuestionada, principal mente debido a las peculiaridades de su forma y a la deficiente transmisión del texto, mas $\mathrm{V}$. Ramón reúne una serie de pruebas que confir man la autoría plutarquea. Como ocurre con otros textos, parece éste una primera redacción que Plutarco no llegó a retocar y acabar. La edición de W. C. Hembold en la Loeb (Londres-Cambridge, Mass., 1968 [=1957]), con algunas variantes procedentes de los códi ces, es la utilizada para la traducción de este opúsculo en forma de diatriba con una primera parte a favor del agua y una segunda que ensal za el fuego. La demostración retórica termina sin decantarse Plutarco por un elemento en concreto. La traducción, sencilla y acertada, se acompaña de unas notas aclaratorias que nos remiten a paralelos en otras partes de la obra de Plutarco, identifican y detallan los personajes, y explican los problemas que plantean espe cialmente algunos juegos de palabras por lo general intraducibies.

V. Ramón destaca en su prólogo el nexo que la tradición literaria establece entre las dos partes de Sobre comer carne y Sobre la inteligencia de los animales y Los animales son racionales debido a su temática sobre la psicología de los animales. Al parecer los textos de Sobre comer carne (pp. 369-397) han sido manipulados por algún compilador tardío, ya que es probable que en un princi pio fueran dos grupos de anotaciones inde pendientes cuya composición Plutarco nunca llegó a pulir y terminar. En forma de diatriba son un alegato en favor del vegeta rianismo y abstinencia en la ingestión de carne, y, al igual que en otros tratados, la introducción nos aclara los puntos en los que Plutarco cuestiona las ideas estoicas. El tono retórico invade por completo ambos textos, cuya forma lleva a pensar a la crítica que es una obra de juventud, y acalla, además, las voces que han negado la autoría plutarquea. El texto empleado procede de la edición de W. C. Hembold en la Loeb (LondresCambridge, Mass., 1968 [=1957]), aunque la más reciente edición de L. Inglese \& G. Santese en D’Auria Editore (Nápoles, 1999) ha proporcionado muchas de las variantes que el traductor utiliza. La traducción salva los problemas que el texto presenta, ofre ciendo una lectura fácil, cuidada y justifica da en el elaborado aparato de notas.

Ana Vicente Sánchez Universidad de Zaragoza 